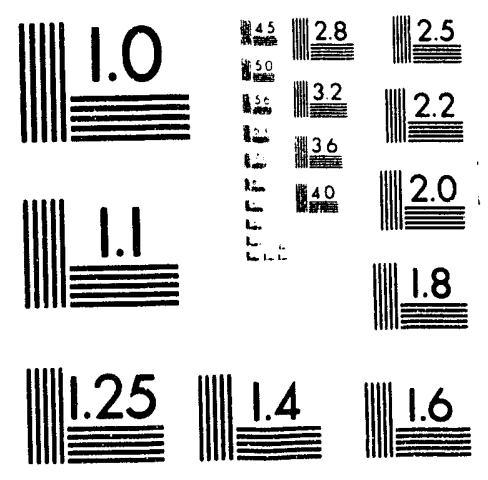



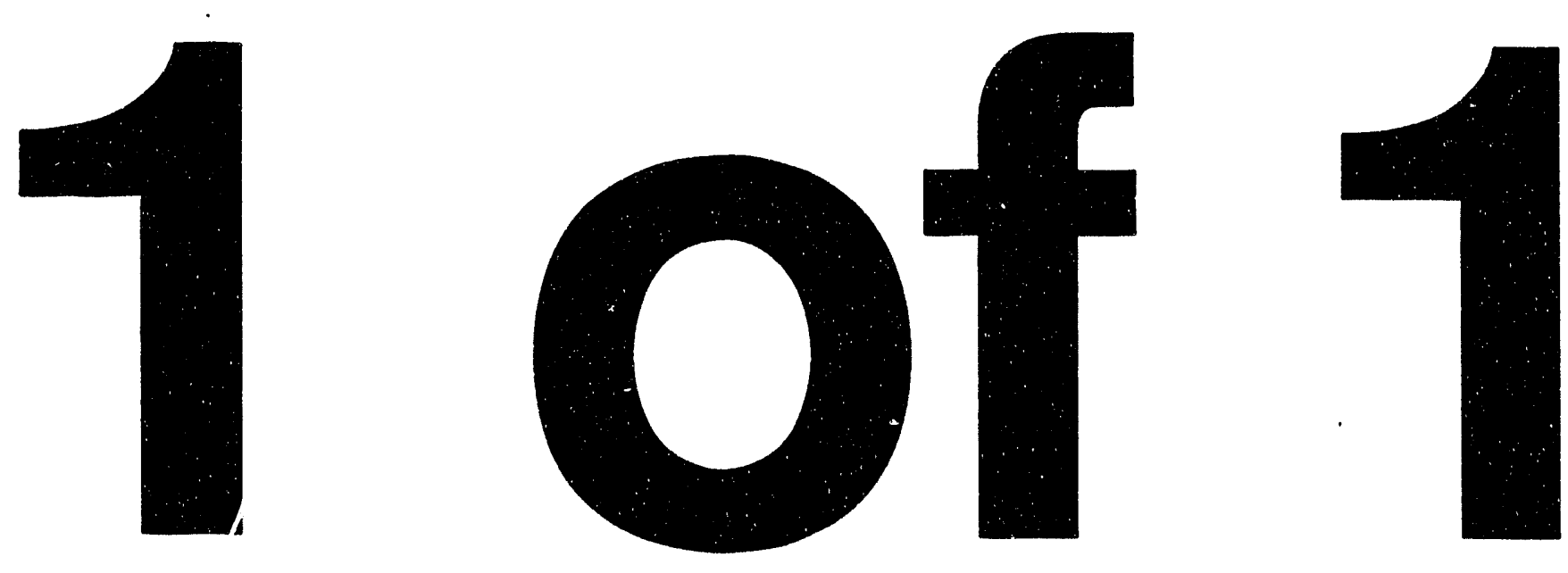


\title{
A MIXTURE MODEL FOR SHOCK COMPRESSION OF POROUS MULTI-COMPONENT REACTIVE MATERIALS
}

\author{
M. R. Baer* \\ Energetic Materials and Fluid Mechanics Dept. 1512 \\ Sandia National Laboratories, Albuquerque,NM, 87185
}

A multiphase mixture model is presented to describe shock compression of highly porous, multi-component powders. Volume fractions are represented as independent kinematic variables and thermodynamicallyadmissable phase interaction constitutive models are formulated in the context of a three phase system. Numerical solutions of the multiphase flow equations simulated impact on a porous layer of mixed powders of $\mathrm{Al}$ and $\mathrm{Fe}_{2} \mathrm{O}_{3}$. The multiphase model predicts dispersive compaction waves which have features similar to observed time-resolved pressure measurements.

\section{INTRODUCTION}

In contrast to single-phase materials, porous materials contain internal boundaries which greatly influence their thermal and mechanical response to shock loading. At the microscaie, heterogeneous materials often have disparate properties and the interactions between constituents greatly influence macroscale response. Much remains to be understood regarding the complex nature of shock compression of distended materials and prior studies have identified anomalous shock behavior in porous materials. For example, experimental studies have shown that Hugoniot descriptions, based on thermodynamic equilibrium, are inaccurate ${ }^{1-3}$ and shock loading induces dispersed compaction wave profiles ${ }^{4-6}$ and material segregation behavior. ${ }^{7}$ Because of the failure of existing models to realistically describe shock behavicr, it is important to extend theoretical models of porous materials.

Continuum mechanics has provided a foundation for theoretical study and mixture theory has successfully described various multiphase waves; $8-10$ however, much of this analysis has centered on two phase models. This work extends mixture theory to a multi-component system. As a preliminary study, impact-induced compaction wave behavior in a porous layer of mixed powders is treated.

\section{THEORETICAL DESCRIPTION}

The foundations of continuum mixture theory are largely based on the works of Truesdell and Toupin ${ }^{11}$ and Truesdell and Noll ${ }^{12}$; an overview of

- This work performed $\alpha$ Sandia National Labarataries supparted by the U.S. Department of Energy under contract DE-ACO4. 760 P00789 theoretical modeling of reactive mixtures can be found in reference 13. In this study, an extension of the multiphase reactive flow model of Baer and Nunziato ${ }^{8}$ is presented; only the final forms of this model are given here. The balance equations are given for a multi-component system with each phase denoted with a subscript " $a$ ". Associated with each phase are the material partial densities, $\rho_{a}=\phi_{a} \gamma_{a}$, true material density, $\gamma_{a}$, volume fractions, $\phi_{a}$, particle velocities, $\vec{v}_{a}$, pressures, $p_{a}$, temperatures, $T_{a}$, and internal energies, $e_{a}$. The Eulerian form of the balance laws are given as:

$$
\begin{aligned}
& \text { Mass: } \quad \dot{\rho}_{a}=-p_{a} \nabla \cdot \vec{v}_{a}+c_{a}^{\dagger} \\
& \text { Momentum: } \quad \rho_{a} \dot{\vec{v}}_{a}=\nabla \cdot g_{a}+\vec{m}_{a}^{\dagger}-c_{a}^{\dagger} \vec{v}_{a} \\
& \text { Energy: } \quad \rho_{a} \dot{e}_{a}=g_{a}: \vec{\nabla}_{\hat{v}_{a}}+e_{a}^{\dagger}- \\
& \left(\vec{m}_{a}^{\dagger}-c_{a}^{\dagger} \vec{v}_{a}\right) \cdot \vec{v}_{a}+c_{a}^{\dagger} E_{a}
\end{aligned}
$$

where the material derivative for each phase is defined as $\dot{f}_{a}=\partial f_{a} / \partial t+\vec{v}_{a} \cdot \vec{\nabla} f_{a}$ and the total energy for each phase is given as $E_{a}=e_{a}+\left(\vec{v}_{a} \cdot \vec{v}_{a}\right) / 2$. The " $\dagger$ " superscript denotes a phase exchange quaqnity for mass, $c_{a}^{\dagger}$, momentum, $m_{a}^{\dagger}$, and energy, $e_{a}^{\dagger}$ and the stresses are represented as $g_{c}=-\phi_{a} p_{a} I+I a$.

Consistent with derivations used in mixture theory, summation of each balance equation over all phases yields the response of the total mixture corresponding to the well known equations of motion for a single phase material. Thus, summation constraints are imposed on the phase interactions: $\sum c_{a}=0, \sum_{a}^{m}=0$ and $\sum_{e}^{+}=0$. The restrictrons of the Second Law of Thermodynamics also suggest admissable forms of phase interaction. For the sake of brevity, the algebraic manipulation will not be repeated here and the final forms of these interactions are given as the following:

\section{DISCLAIMER}

This report was prepared as an account of work sponsored by an agency of the United States Government. Neither the United States Government nor any agency thereof, nor any of their employees, makes any warranty, express or implied, or assumes any legal liability or responsibility for the accuracy, completeness, or usefulness of any information, apparatus, product, or process disclosed, or represents that its use would not infringe privately owned rights. Reference herein to any specific commercial product, process, or service by trade name, trademark, manufacturer, or otherwise does not necessarily constitute or imply its endorsement, recommendation, or lavoring by the United States Government or any agency thereof. The views and opinione of authors expressed herein do not necessarily state or reflect those of the United States Government or any agency thereof. 


$$
\begin{gathered}
\vec{m}_{a}^{\dagger}-c_{a}^{\dagger}\left(\hat{v}_{a}+\vec{v}_{i}\right) / 2+p_{i} \nabla \phi_{a}=\sum_{j} \delta_{j, a}\left(\hat{v}_{j}-\hat{v}_{a}\right) \\
e_{a}^{\dagger}-\vec{m}_{a} \cdot \hat{v}_{a}-\left(e_{a}-\hat{v}_{a} \cdot \hat{v}_{a} / 2\right) c_{a}^{\dagger}- \\
\left(\beta_{a}-p_{a}\right)\left\{\grave{\phi}_{a}-\varepsilon_{a}^{\dagger} / \gamma_{a}\right\}=\sum_{j} \mathcal{H}_{j, a}\left(T_{j}-T_{a}\right) \\
\dot{\phi}_{a}-\varepsilon_{a}^{\dagger} / \gamma_{a}=\sum_{j} \tau_{j, a}\left(p_{a}-\beta_{a}-p_{j}+\beta_{j}\right)
\end{gathered}
$$

where $\delta_{j, a}, H_{j, a}, \tau_{j, a}$ are exchange coefficients of positive-definite symmetric tensors reflecting interactions between phases. Interface quantities are denoted with a subscript " $i$ ". The configurational stress, $\beta_{a}$, is the stress associated with contact forces between phases and is a different stress state than the bulk stress associated with the material compressibility. Model closure is obtained by specifying an independent equation of state for each phase. Hence, the mixture description centers on the determination of appropriate constitutive relations and phase exchange coefficients using micromechanical modeling and/or experimental guidance.

\section{A MODEL APPLICATION}

Time-resolved measurements of shock wave structure in porous multicomponent powders are recent advances in the shock physics field; ${ }^{4-6}$ hence limited data exists for guidance in theoretical studies. Figure 1 displays a set of wave profiles measured using PDVF gauges between a porous layer of $2 \mathrm{Al} / \mathrm{Fe}_{2} \mathrm{O}_{3}(2.33 \mathrm{~g} / \mathrm{cc})$ mixed powders and a layer of Kel F. Varied impact conditions are shown of the output pressure shifted in time to a common datum. The striking feature of these records is the dispersive nature of the shock front. Rise times of 50 to $300 \mathrm{~ns}$ were measured which are well in excess of the rise time in crystalline solids.

As an application of the mixture theory, a 6.7 kbar impact on a $4 \mathrm{~mm}$ layer of mixed $2 \mathrm{Al} / \mathrm{Fe}_{2} \mathrm{O}_{3}$ has been modeled. The mixture description is formulated to describe three components - two solid constituents and void. As an approximation, we consider equal phase velocities $\left(\delta_{j, a} \rightarrow \infty\right)$ and an impact condition that is insufficient to produce reaction between the phases, $\left(\varepsilon_{s}^{\dagger} \rightarrow 0\right)$. Thus, the model description simplifies to a set of mass conservation equation;, a set of energy equations including heat transfer effects between the solid phases, a set of volume fraction rate equations describing variations

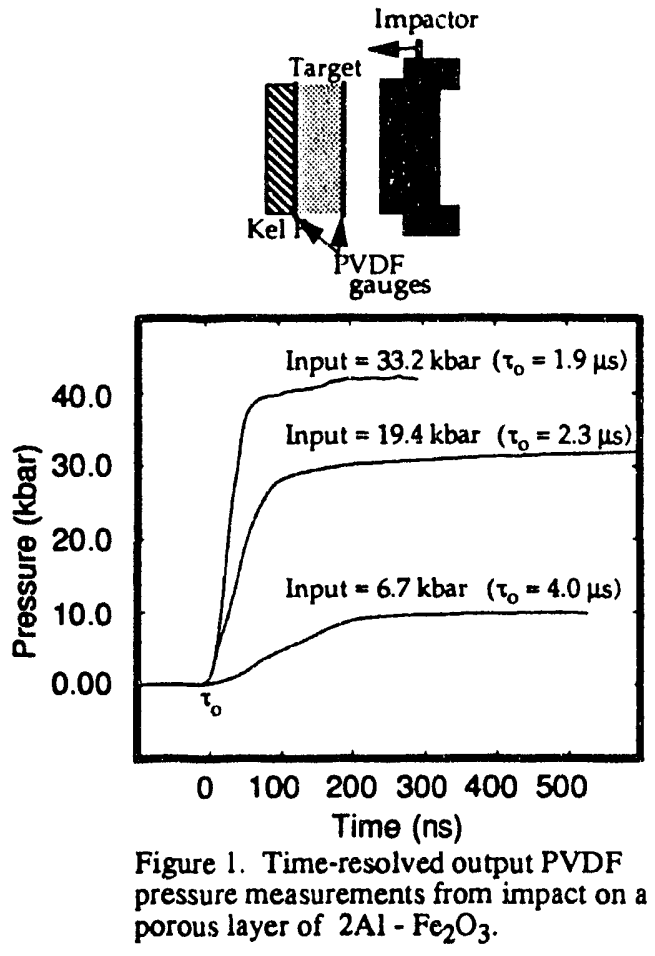

due to difference in the stress fields, and a single momentum equation describing the mass-averaged velocity of the mixture. Separate thermoelastic equations of state for $\mathrm{Al}$ and $\mathrm{Fe}_{2} \mathrm{O}_{3}$ are formulated using shock Hugoniot data for the crystalline materials ${ }^{14}$. To model the configurational stress, $\beta_{a}, \mathrm{em}$ pirical Konopicky relationships 15 are formulated using yield stresses for each phase ${ }^{16,17}$. Finally, the exchange coefficients for the volume fraction rate equations, $\tau_{j, a}$, are inversely related to material viscosities which are scaled to material sound speed and particle size.

One-dimensional numerical solution of the mixture model is sought using an adaptive finite element method ${ }^{18}$ resolving appropriate length scales associated with the shock compression of the porous material. Figure 2 displays an overlay of the pressure, volume fraction and temperature profiles for each solid phase material projected in distancetime space. Input impact conditions occur at the origin of the spatial coordinate. As shown in these plots, compaction of interacting solids proceeds as a dispersive compaction wave traversed the porous layer. Upon interacting with the boundary between the porous material and the Kel F (at the $4 \mathrm{~mm}$ spatial coordinate) an impedance mismatch produces a reflected wave back into the compacted material. 

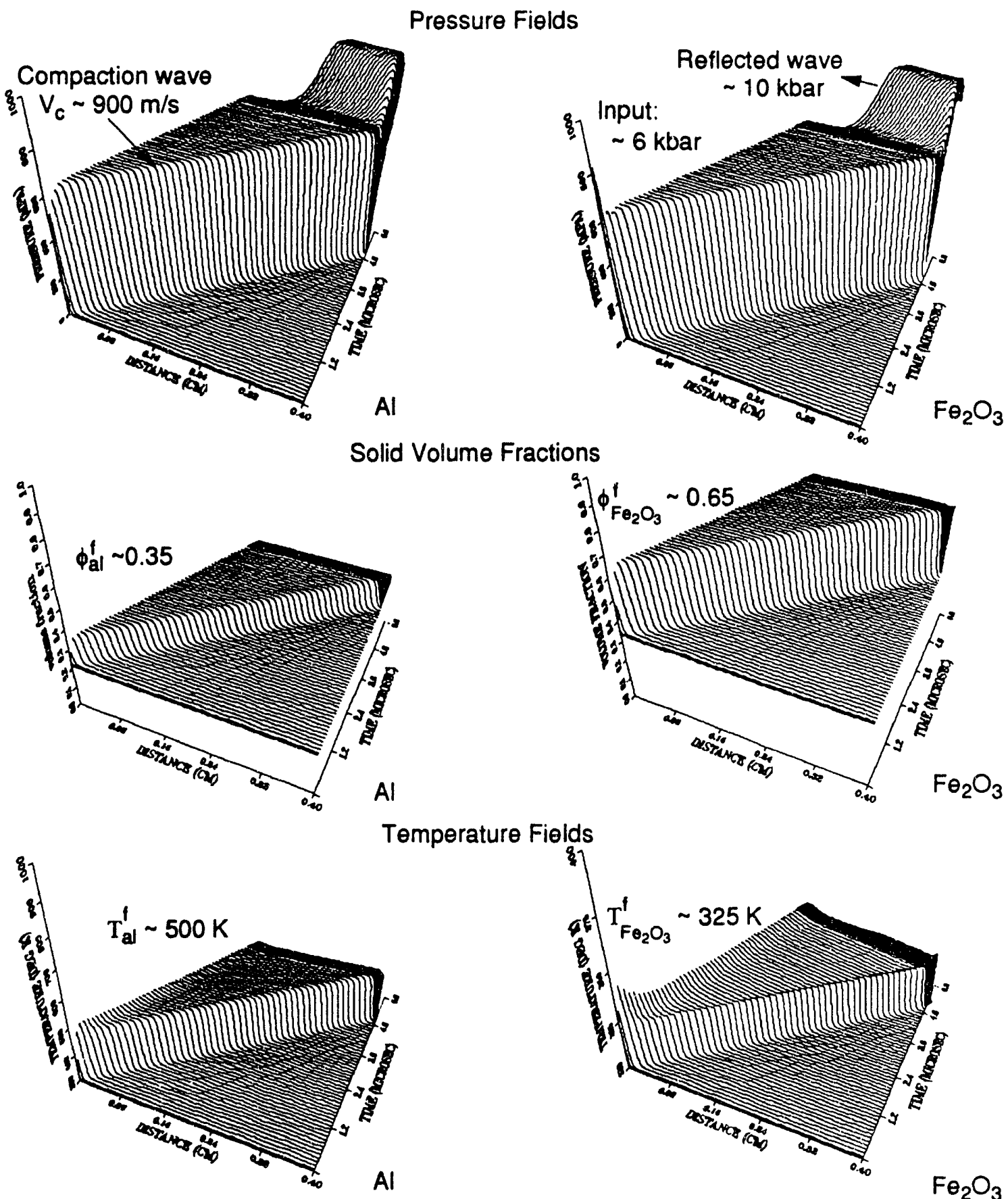

Temperature Fields

Figure 2. Calculated compaction wave fields in a porous layer of $2 \mathrm{Al} / \mathrm{Fe}_{2} \mathrm{O}_{3}$ following a $6.7 \mathrm{Kbar}$ impact. Figures in the left column correspond to $\mathrm{Al}$ pressure, volume fraction, and temperature (top to bottom) and the right column figures are $\mathrm{Fe}_{2} \mathrm{O}_{3}$ fields. 
At a $6.7 \mathrm{kbar}$ input condition, the compaction shock wave has a speed of $-900 \mathrm{~m} / \mathrm{s}$ yielding a delay of $\sim 4.5 \mu \mathrm{s}$ between the input and output gauge locations similar to experimental observation. Upon interaction with the Kel F boundary, the pressure rises to $\sim 10 \mathrm{kbar}$ in a duration of $\sim 200 \mathrm{~ns}$. This corresponds to a wave thickness of $-0.1 \mathrm{~mm}$. Pressure differences between the phases occur primarily at the compaction wave front.

The transient solid volume fraction profiles clearly shows that rapid distortion of the powders occur in a thin shock-like compaction wave which traverse the porous layer. Initially, the volume fractions for $\mathrm{Al}$ and $\mathrm{Fe}_{2} \mathrm{O}_{3}$ are $\sim 0.2$ and 0.35 , respectively and material flow during compaction increases the volume fractions to 0.35 and 0.65 . This suggests that the majority of the material distortion is associated with $\mathrm{Fe}_{2} \mathrm{O}_{3}$ and all of the open porosity is filled following compaction. Recovery tests on shock compressed powders have suggested similar behavior.

The temperature fields show that thermodynamic equilibrium does not occur during shock compression (at these impact conditions). A larger temperature rise occurs in the consolidated $\mathrm{Al}$ than in the $\mathrm{Fe}_{2} \mathrm{O}_{3}$, however, both temperatures fields are below melting conditions. For this powder configuration (mean particle sizes 15 and $22 \mu \mathrm{m}$ for $\mathrm{Al}$ and $\mathrm{Fe}_{2} \mathrm{O}_{3}$ powder, respectively), heat transfer is insufficient to rapidly equilibrate these temperatures and thermodynamic equilibrium occurs at much longer time scales.

\section{SUMMARY}

In this study, a multi-component mixture model for shock compression of porous materials is presented. This model has been applied to the simulation of impact on a layer of mixed metal powders and predicted wave behavior favorably reproduce experimental observations. Extended study of this approach will now focus on experimental studies of mixed powders with greatly disparate thermophysical properties and conditions which will initiate reactive wave behavior. Prediction of combustion response to shock loading represents the forefront of energetic material research and determining the nature of dispersive shock wave structure in porous materials is a critical step toward a better understanding of the complex reactive behavior of composite materials.

\section{ACKNOWLEDGMENTS}

I would like to thank R. A. Graham for insightful discussions and suggestions in the course of this study. I also thank G. T. Holman, R. A. Graham and $M$. U. Anderson for sharing their PVDF measurements used in this work.

\section{REFERENCES}

1 Trofimov, V. S., G. A Adadurow. S. V. Pershin and A. N. Dremin. "Anomalous Shock Compressibility of Porous Materials". Combustion, Explosion and Shock Waves, Vol 4. No. 2. pp. 244-253. 1968.

2 Linde, R. K. and D. N. Schmidt, “Shock Propagation in Nonreactive Porous Solids", Journal of Applied Physics, Vol 37. No. 8., pp 3259-3271, 1966.

3 Dolgoborodow. A. Y.. I. M.Voskoboinikov, I. K. Tolstov and A. V. Sudarilov. "Anomalies of the Propagation of Shock Waves in Mixtures". Combustion, Explosion and Shock Waves, Vol. 28, No.3. pp. $106-111,1992$.

4 Holman G. T. R. A. Grabam M. U. Anderson. "Shock Response of Porous $2 \mathrm{Al}+\mathrm{Fe}_{2} \mathrm{O}_{3}$ Mixtures". 1993 Topical Conference on Shock Compression of Condensed Matter. Colorado Springs, CO, 1993.

5 Anderson. M. U.. R. A. Graham, and G. T. Holman, "Time-Resolved Shock Compression of Porous Rutile". 1993 Topical Conference on Shock Compression of Condensed Matter, Colorado Springs. CO. 1993.

6 Dunbar, E. R. A. Graham, N. N. Thadhani, "Time-Resolved Pressure Measurements in Chemically Reacting Powder Mixtures".1993 Topical Conference on Shock Compression of Condensed Matter. Colarado Springs, CO. 1993.

7 Kostyukov. N. A. "Mechnnism of Lamination of Particulate Composites in Shock Loading". J. Applied Mechanics and Technical Physics, No 1. pp. 84-91, 1990

8 Baer. M.R. and Nuzziato. J. W.. "A Two-Phase Mixture Theory for the Deflagration-to-Detonation Transition (DDT) in Reactive Granular Materials," International Journal of Multiphase Flow, Vol 12. no. 6. 1986, pp. 861-889.

9 Baer. M. R. "A Numerical Study of Shock Wave Refloction on Low-Density Foam," Shock Waves, Vol. 2, pp 121-124., 1993.

10 Baer, M. R "Wumerical Studies of Dynamic Compaction of Inert and Energetic Granular Materials," Journal of Applied Mechanics, Vol. 55. 1988, pp. 36-43.

11 Truesdell, C. and R. Toupin. "The Classical Field Theories". Handbuck der Physik (Ed. S. Flugge). Vol II/1. Berlin: Springer. 1960.

12 Truesdell. C. and N. Noll. "The Nonlinear Field Theories of Mechanics", llandbuck der Physik (Fd. S. Flugge), Vol $\mathrm{m} / 3$ r. Berlin: Springex, 1965.

13 Truesdell, C., Rational Thermodynamics, 2nd Edition. Springer-Verlag 1984.

14 Marsh S. P.. LASL Shock Hugoniot Data, University of California Press, 1980.

15 Konopicky, K., Radex Rdsch. Vol 3, p 141, 1948.

16 Wang, P. T. and M. A. Zaidi. "Thenmomechanical Deformation of Powder-Based Porous Aluminum - part $\Gamma^{\prime}$. Powder Technology. Vol 66. pp 9-19, 1991.

17 Prasad, Y. A tand Y. B. G. Varma. "Physical and Mechanical Properties of a-Iron Oxide, Iron Oxide-Alumina and Niclael-Alumira Catalysts". Indian Journal of Technology. Vol 18. pp. 122-126, 1990 .

18 Baer. M. R. Menner, R. E. Gross. R. J., and Nunziato. J. W. "Modeling ax' Computation of Deflagration-to-Detonation Transition (DTYT) in Reactive Granular Materials," Lectures in Applied Mathernatics. American Mathematical Society. Vol. 24. 1986, pp. 479-498. 

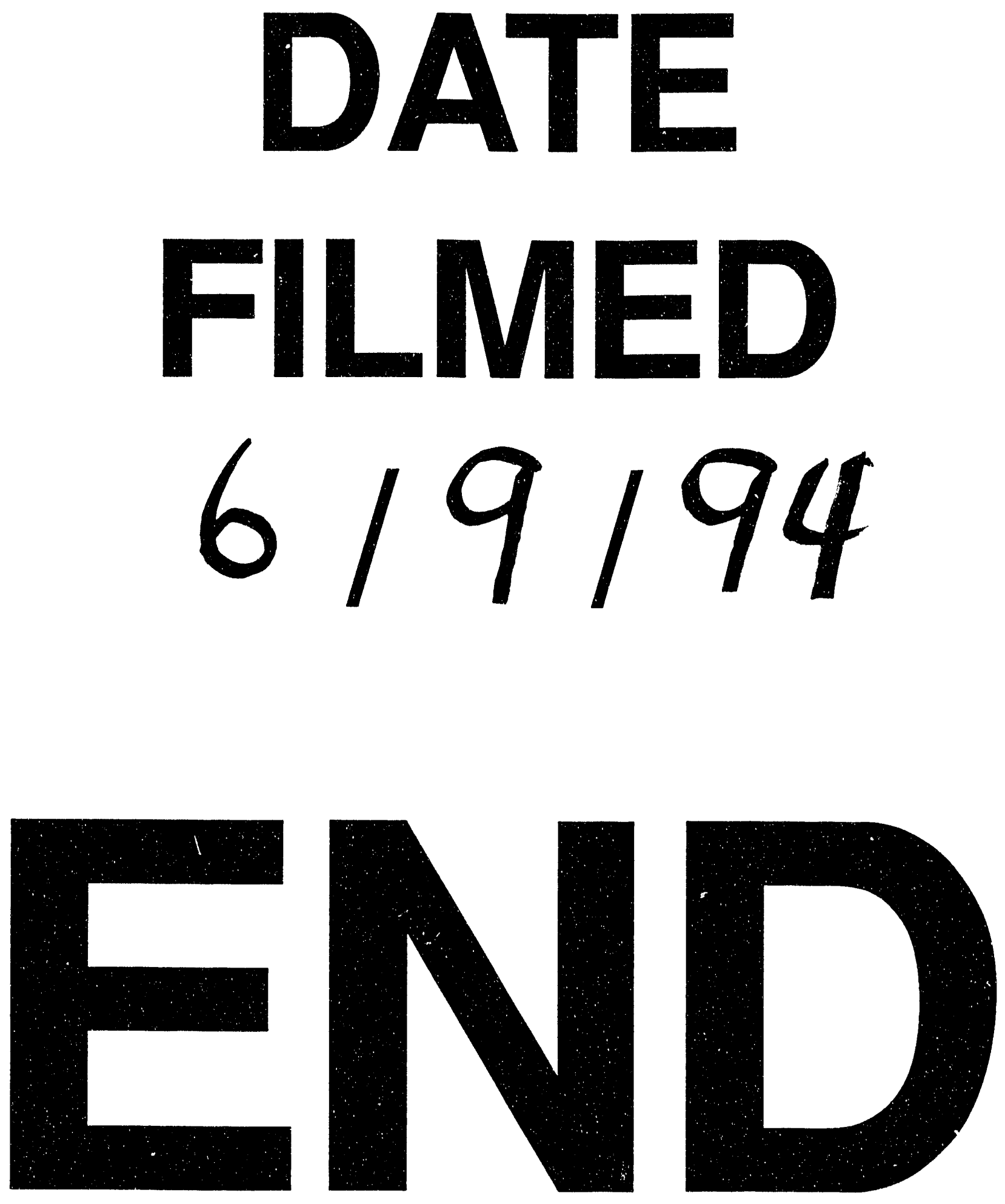
